\title{
Dental caries in schoolchildren: influence of inattention, hyperactivity and executive functions
}

\section{Isabella MOTA-VELOSO(a) Maria Letícia RAMOS-JORGE(b) Marcio Alexandre HOMEM(a) Isabela Almeida PORDEUS(a) Saul Martins PAIVA ${ }^{(a)}$ Fernanda OLIVEIRA-FERREIRA(c)}

(a) Universidade Federal de Minas Gerais UFMG, School of Dentistry, Department of Pediatric Dentistry, Belo Horizonte, MG, Brazil.

(b) Universidade Federal dos Vales do Jequitinhonha e Mucuri - UFVJM, School of Dentistry, Department of Pediatric Dentistry and Orthodontics, Diamantina, MG, Brazil.

(c) Universidade Federal de Juiz de Fora (UFJF), Department of Basic Sciences, Governador Valadares, MG, Brazil.

Declaration of Interest: The authors certify that they have no commercial or associative interest that represents a conflict of interest in connection with the manuscript.

\section{Corresponding Author:}

Maria Letícia Ramos-Jorge

E-mail: mlramosjorge@gmail.com

https://doi.org/10.1590/1807-3107bor-2018.vol32.0052

Submitted: July 12, 2017

Accepted for publication: April 13, 2018

Last revision: May 03, 2018
Abstract: Attention-deficit/hyperactivity disorder (ADHD) is characterized by inappropriate levels of hyperactivity, impulsivity, and/or inattention. Individuals with ADHD may present limitations with regard to executive functions and performing activities that involve planning and/or attention/concentration. The aim of the study was to investigate the association between dental caries and signs of ADHD in a representative sample of schoolchildren. A representative sample of 851 schoolchildren aged seven to 12 years was randomly selected from public and private schools. Data acquisition involved a clinical dental examination for cavitated permanent and deciduous teeth using the DMFT/dmft indices. Neuropsychological evaluations, including the assessment of intelligence (Raven's Colored Progressive Matrix Test) and executive functions (Corsi Tapping Blocks tests and Digit Span test) were also performed. Parents/caregivers and teachers answered the SNAP-IV Questionnaire for the investigation of signs of inattention and hyperactivity in the family and school environment. Parents/caregivers also answered questionnaires addressing socioeconomic and sociodemographic characteristics. Descriptive analysis of the variables and Poisson regression with robust variance were performed. Parental reports of signs of inattention (PR: 1.28; $\mathrm{p}<0.05)$ and hyperactivity (PR: 1.15; $\mathrm{p}<0.05$ ) were associated with a greater occurrence of caries. A better performance on the backward order of the Corsi Tapping Blocks tests (PR: 0.94; $\mathrm{p}<0.05)$ and higher level of mother's schooling were associated with a lower frequency of caries. A better performance on executive function tasks was a protective factor against dental caries, whereas children considered inattentive and/or hyperactive by their parents had a higher prevalence rate of dental caries.

Keywords: Attention Deficit Disorder with Hyperactivity; Dental Caries; Executive Function.

\section{Introduction}

Attention-deficit hyperactivity disorder (ADHD) is a common neuropsychiatric disorder characterized by a persistent, developmentally inappropriate pattern of inattention, hyperactivity, and/or impulsivity. ${ }^{1}$ Studies report prevalence rates of ADHD ranging from $2.0 \%$ to $18.0 \%{ }^{2,3,4}$ This relatively wide range is due to the different diagnostic criteria adopted 
in different studies as well as the characteristics of the analyzed population. ${ }^{5}$

Individuals affected by ADHD may experience problems with activities of daily living, family stress, poor academic performance, and low self-esteem. ${ }^{6,7}$ Such individuals also tend to have some degree of impairment with regard to executive functions, which limits the performance of activities that involve organization, planning, concentration, monitoring one's own behavior, and cognitive flexibility. ${ }^{4,8}$

As the number of children diagnosed with ADHD increases every year' ${ }^{9}$, dentists often encounter patients with this disorder. There is evidence that children with ADHD have greater difficulty in maintaining adequate oral hygiene and may present more oral problems. ${ }^{10,11}$ However, the scientific literature remains inconclusive regarding the dental implications of ADHD and associated factors. ${ }^{12}$ Although some studies report an association between ADHD and a higher occurrence of dental caries ${ }^{5,10,11,13}$, others have not found such an association. ${ }^{14,15}$ Moreover, a large portion of investigations have been conducted with non-representative samples and the specific influence of signs of inattention/hyperactivity and executive functions on the occurrence of dental caries has not been investigated in a representative sample of schoolchildren. ${ }^{4,10,11,13}$ Thus, the aim of the present study was to evaluate the association between the occurrence of dental caries and ADHD (signs reported by parents/caregivers and teachers and an assessment of cognitive functioning) in a representative sample of schoolchildren.

\section{Methodology}

\section{Sample}

A representative, cross-sectional study was conducted with children aged seven to twelve years attending public and private schools in the city of Diamantina, Brazil. The participants were randomly selected based on the population distribution of children in schools: municipal public schools (70\%), state public schools (20\%), and private schools (10\%). The exclusion criteria were the use of an orthodontic appliance, intellectual disability (children scoring at or below the $5^{\text {th }}$ percentile of Raven's Colored
Progressive Matrices test) or neurological disease (based on parental report).

To calculate the sample size, an unknown prevalence rate of $50 \%$ was considered, since no data were found on the prevalence of caries in this age group in the city of Diamantina and this rate gives the largest sample size. Using a 95\% confidence interval, $4 \%$ acceptable estimate error and a design effect of 1.2, as two-stage sampling was performed (schools, followed by classes), the minimum sample size was determined to be 720 participants. To compensate for possible dropouts, the sample was increased by 194 individuals, totaling 914 children.

\section{Data collection}

Before the clinical examination, the child was instructed to perform tooth brushing. During the examination, the child remained seated in a chair in front of the examiner in a private room at the school. A head lamp (PETZL, Tikka XP, Crolles, France), disposable mouth mirror (PRISMA, São Paulo, SP, Brazil), periodontal probe (Trinity, Campo Mourão, PA, Brazil) and gauze were used and all procedures complied with bio-safety norms. The criteria of the World Health Organization ${ }^{16}$ were used for the evaluation of cavitated permanent and deciduous teeth considering only the decayed component of the decayed, missing and filled teeth (DMFT/dmft) indices. The absence of untreated cavitated teeth was recorded when $\mathrm{D}+\mathrm{d}=0$ and the presence of untreated cavitated teeth was recorded when $\mathrm{D}+\mathrm{d} \geq 1$.

\section{Training and calibration of examiners}

A team consisting of five dentists and five assistants was responsible for conducting the dental examinations. The examiners had undergone both theoretical and practical exercises for the diagnosis of dental caries. Weighted Kappa coefficients were calculated for the determination of inter-examiner and intra-examiner agreement. All Kappa values were higher than 0.7. Another team composed of four examiners was also responsible for conducting the neuropsychological tests. The analysis and interpretation of neuropsychological tests were performed by a psychologist (FOF). 


\section{Neuropsychological evaluation}

The neuropsychological evaluation involved the assessment of intellectual function (Raven's Colored Progressive Matrices test) and executive functions (Corsi Block Tapping test and the Digit Span test).

\section{Intellectual function}

Raven's Colored Progressive Matrices test is the gold standard for intellectual assessments. It consists of a set of reasoning tasks for the evaluation of fluid intelligence and is therefore less affected by contextual variables. The test consists of three sets of 12 items (total: 36 items). Each item is a drawing of a pattern with one piece missing and six options offered to complete the pattern. One point is awarded for each correct response. The test has been normalized for children from five to 12 years of age and validated for use on the Brazilian population. ${ }^{17}$ The result is scored as a percentile compared to norms. Percentiles equal to or less than five indicate that the child's abstract reasoning is lower than $95 \%$ of the population of children of the same age and therefore suggests intellectual disability. In the present study, children scoring at or below the 5 th percentile were excluded to avoid a confounding factor.

\section{Executive functions}

The Digit Span test is used to evaluate short-term memory and working memory storage capacity. In the forward order portion of the test, the participant is asked to repeat a set of random numbers given orally by the examiner; a new digit is added to the sequence with each correct repetition. In the backward order, the participant must repeat the set of numbers in the reverse (backward) sequence dictated by the examiner for the evaluation of the executive component of short-term memory. The total score is computed by the maximum number of digits the participant can repeat correctly in each step. ${ }^{18}$

The Corsi Block Tapping test is used to evaluate the reach of short-term memory by employing visuospatial memory. The participant is instructed to repeat a sequence of movements performed by the examiner by touching blocks on a board. As in the Digit Span test, the participant repeats the sequence in the forward order during the first step of the test and the backward order in the second step. The total score is determined by the maximum number of sequences (span) the participant can reproduce. ${ }^{19}$

\section{Assessment of signs of inattention and hyperactivity}

The Swanson, Nolan, and Pelham Scale (SNAP - IV) is used for the evaluation of child behavior through subscales that address inattention, hyperactivity/impulsivity, and defiant/oppositional behavior. In the present study, only the subscales for the evaluation of inattention and hyperactivity/ impulsivity (nine items each subscale) were used. SNAP IV was answered by parents/caregivers and teachers to compare the behavioral patterns reported in the family and school environment, which is part of the diagnostic criteria for ADHD. Each item is scored from 0 to 3 (not at all $=0$; "just a little" $=1$, "quite a bit"= 2, and "very much" = 3). SNAP-IV scores are calculated by summing the item scores in the specific subset (e.g., inattention, hyperactivity) and dividing by the number of items in the subset (Table 1). The score of any subset is reported as the average rating per item. Five percent cutoff scores are provided for teachers and parents. If the results are higher than the cutoffs, significant inattention and/ or hyperactivity is considered. There are different cutoffs for teachers and parents. For inattention, the cutoff is 2.56 for teachers and 1.78 for parents. For hyperactivity, the cutoff is 1.78 for teachers and 1.44 for parents. In the present study, data analysis was conducted separately for the scores attributed by the teachers and parents to assess child behavior in both environment (family and school). ${ }^{20}$

\section{Socioeconomic/socio-demographic characteristics}

Parents/caregivers filled out a socio-demographic questionnaire addressing the sex and age of the child, parents' marital status, parental education level, and household income (total monthly earning of all members of the household measured in Brazilian currency ( $\mathrm{R} \$$ ) and categorized based on the Brazilian monthly minimum wage - approximately US\$ 300), and number of individuals living on the same income. 
Table 1. Description of SNAP IV scale items.

\begin{tabular}{ll}
\hline For each item, select the box that best describes this child. Put only one check per item. \\
\hline Inattention \\
\hline 1 & Often fails to give close attention to details or makes careless mistakes in schoolwork, work, or other activities \\
2 & Often has difficulty sustaining attention in tasks or play activities \\
3 & Often does not seem to listen when spoken to directly \\
4 & Often does not follow through on instructions and fails to finish schoolwork, chores, or duties \\
5 & Often has difficulty organizing tasks and activities \\
6 & Often aroids, dislikes, or is reluctant to engage in tasks that require sustained mental effort (e.g., schoolwork or homework) \\
7 & Often loses things necessary for tasks or activities (e.g., toys, school assignments, pencils, books, or tools) \\
8 & Often is distracted by extraneous stimuli \\
9 & Often is forgetful in daily activities \\
\hline Hyperactivity & Often fidgets with hands or feet or squirms in seat \\
\hline 10 & Often leaves seat in classroom or in other situations in which remaining seated is expected \\
12 & Often runs about or climbs excessively in situations in which it is inappropriate \\
13 & Often has difficulty playing or engaging in leisure activities quietly \\
14 & Often is "on the go" or often acts as if "driven by a motor" \\
15 & Often talks excessively \\
16 & Often blurts out answers before questions have been completed \\
17 & Often has difficulty awaiting turn \\
18 & Often interrupts or intrudes on others (e.g., butts into conversations/games) \\
\hline
\end{tabular}

\section{Data analysis}

Data analysis was conducted using the Statistical Package for Social Sciences (SPSS for Windows, version 20.0; SPSS Inc., Chicago, USA). Descriptive statistics (absolute and relative frequencies) were first performed. The Kolmogorov-Smirnov test was used to determine the normality of the data. The chi-square test was used to investigate associations between categorical variables and the occurrence of dental caries. The Mann-Whitney U-test was employed to investigate associations between quantitative variables (neuropsychological data) and the occurrence of caries. Poisson regression models with robust variance were created to determine which variables significantly explained the occurrence of caries. Independent variables that achieved a p-value $<0.20$ in the bivariate analysis and those with a theoretical justification were incorporated into the univariate analysis. The Poisson regression model followed a hierarchical approach from distal to proximal determinant $^{21}$ : a) characteristics of the child; b) sociodemographic factors; and c) psychological factors. For each level, Poisson regression with robust variance was performed to determine associations between the independent variables and dental caries (presence) absence). Explanatory variables with a $p$-value $<0.05$ after adjustment for other variables on the same level and previous level were selected for the multivariate model. Prevalence ratios (PR) and 95\% confidence intervals (CI) were calculated. The level of significance was set at $5 \%$.

\section{Ethical aspects}

This study was conducted in compliance with international statutes and national legislation on ethics in research involving human subjects and received approval from the Human Research Ethics Committee of Universidade Federal dos Vales do Jequitinhonha e Mucuri (Brazil) under process number 045/2011. All parents/ guardians signed a statement of informed consent. This investigation was conducted in full accordance with ethical principles, including those stipulated in the Declaration of Helsinki by the World Medical Association.

\section{Results}

Among the 914 participants selected, 63 were excluded due to intellectual deficit ( 25 children), refusal to allow dental examination (7 children), and undergoing orthodontic treatment (31 children). Thus, the final sample consisted of 851 children (Figure 1). The mean age of the children was 9.39 years $(\mathrm{SD}=1.68)$ and $54.8 \%$ 
were female. More than half had a household income of up to two times the Brazilian monthly minimum wage and $74.60 \%$ of the families had four or more individuals who depended on this income.

Regarding the signs of ADHD, inattention was reported more by teachers $(9.50 \%)$ than parents/ caregivers $(5.90 \%)$ and hyperactivity was reported more by parents/caregivers (15.30\%) than teachers $(9.90 \%)$. Considering the presence of symptoms in the two contexts, the prevalence of inattention and hyperactivity was estimated at $2.40 \%$ and $3.80 \%$, respectively. Table 2 displays the distribution of the socioeconomic and neuropsychological variables.

The prevalence of untreated cavitated deciduous and permanent teeth was $53.2 \%$. An association was found between the presence of caries and reports of inattention by parents/caregivers, reports of hyperactivity by parents/ caregivers, household income, and mother's schooling
(Table 3). In the comparison between groups (without cavitated teeth and with cavitated teeth), significant differences were found for the Corsi Block Tapping test (backward order) and Raven's Colored Progressive Matrices (Table 4), as children without cavitated teeth had significantly higher performances on these tasks.

In the univariate Poisson regression analysis, household income and mother's schooling (socioeconomic variables) were associated with the occurrence of caries. Among the neuropsychological variables, the occurrence of dental caries was significantly associated with parental report of inattention, agreement between parents/caregivers and teachers regarding inattention, parental report of hyperactivity, and performance on the forward Digit Span test, Corsi Block Tapping test, and Raven's Colored Progressive Matrices test (Table 5).

After the univariate analysis, the occurrence of multicollinearity was analyzed before incorporating the
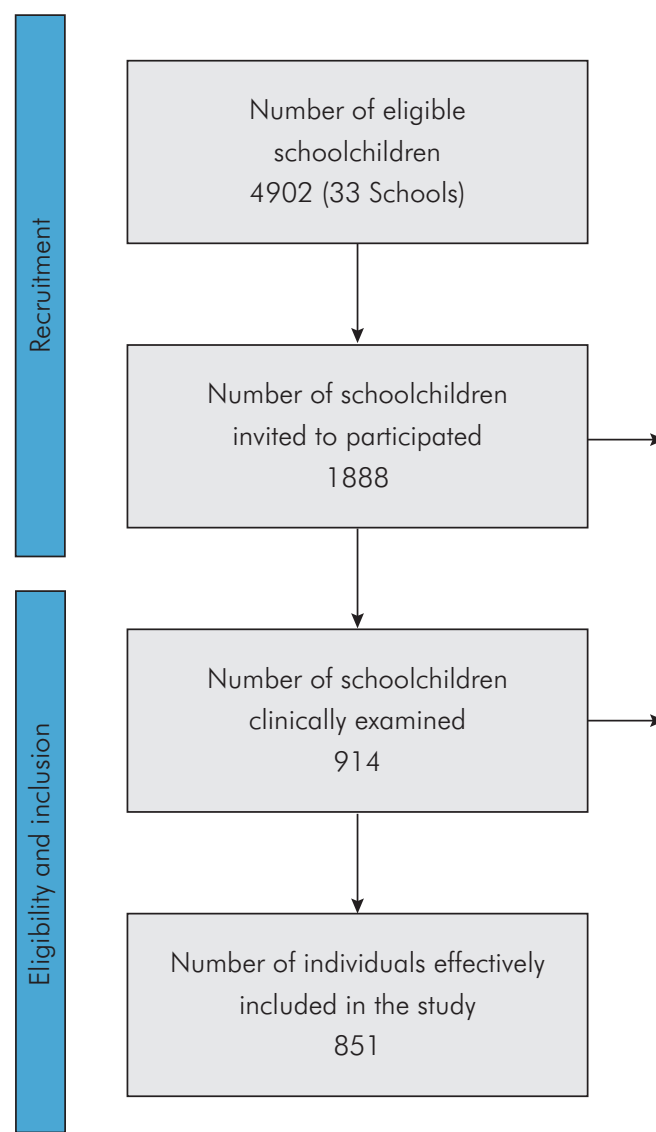

Reasons why children did not participate in study 544 Lack of informed consent 302 Children refused to participate 112 Not at school on day of data collection 16 Changed school
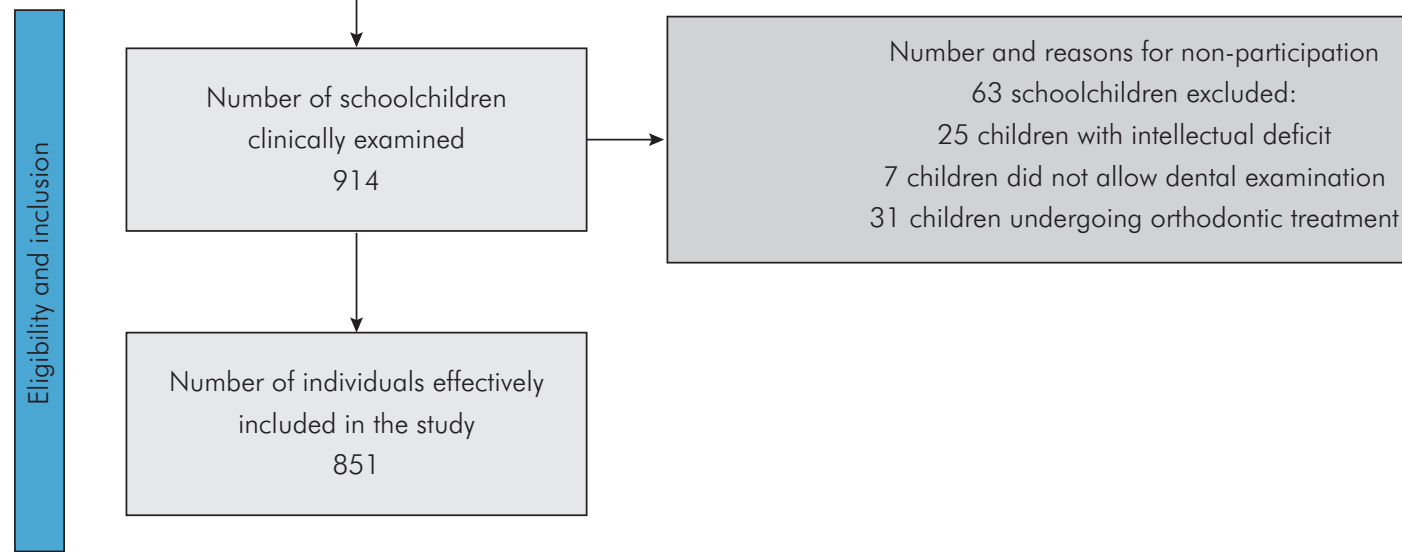

Figure 1. Flowchart of participant selection process. 
Table 2. Frequency of socioeconomic and neuropsychological variables.

\begin{tabular}{|c|c|c|}
\hline Variables & $\mathrm{n}$ & $\%$ \\
\hline \multicolumn{3}{|l|}{ Child's sex } \\
\hline Male & 385 & 45.20 \\
\hline Female & 466 & 54.80 \\
\hline \multicolumn{3}{|l|}{ Marital status of mother or guardian } \\
\hline Not married & 183 & 21.70 \\
\hline Married & 458 & 54.30 \\
\hline Divorced & 81 & 9.50 \\
\hline Other & 122 & 14.50 \\
\hline \multicolumn{3}{|l|}{ Household income } \\
\hline Less than BMMW & 108 & 12.80 \\
\hline One to less than two times BMMW & 387 & 45.80 \\
\hline Two to less than five times BMMW & 252 & 29.80 \\
\hline Five BMMW or more & 98 & 11.50 \\
\hline \multicolumn{3}{|l|}{ Number of individuals living on income } \\
\hline Two or three & 213 & 25.40 \\
\hline Four or five & 478 & 57.00 \\
\hline Six or seven & 110 & 13.10 \\
\hline Eight or nine & 25 & 3.00 \\
\hline Ten or more & 13 & 1.50 \\
\hline \multicolumn{3}{|l|}{ Mother's schooling } \\
\hline Incomplete primary school & 209 & 24.70 \\
\hline Complete primary education & 88 & 10.40 \\
\hline Incomplete high school & 51 & 6.00 \\
\hline Complete high school & 288 & 34.00 \\
\hline Higher education & 210 & 24.80 \\
\hline \multicolumn{3}{|l|}{ SNAP-IV } \\
\hline \multicolumn{3}{|l|}{ Inattention } \\
\hline Reported by parents & 50 & 5.90 \\
\hline Reported by teachers & 81 & 9.50 \\
\hline Reported in both contexts (agreement) & 20 & 2.40 \\
\hline \multicolumn{3}{|l|}{ Hyperactivity } \\
\hline Reported by parents & 130 & 15.30 \\
\hline Reported by teachers & 84 & 9.90 \\
\hline Reported in both contexts (agreement) & 32 & 3.80 \\
\hline
\end{tabular}

* BMMW: Brazilian monthly minimum wage

variables into the multivariate model. The chi-square test demonstrated that household income and mother's schooling were significantly associated $(p<0.001)$. Thus, to avoid the occurrence of multicollinearity, only mother's schooling was chosen for the model as this variable is considered a precise socioeconomic indicator and was more significantly associated with the outcome. Moreover, mother's schooling has often been used as one of the best predictors of children's health, especially in developing countries. ${ }^{22}$

In the analysis of the multicollinearity among the psychological variables, the SNAP-IV items parental
Table 3. Association between variables and occurrence of cavitated teeth

\begin{tabular}{lcccccc}
\hline Variables & \multicolumn{1}{c}{$\begin{array}{c}\text { Without } \\
\text { cavitated } \\
\text { teeth }\end{array}$} & \multicolumn{2}{c}{$\begin{array}{c}\text { With } \\
\text { cavitated } \\
\text { teeth }\end{array}$} & \multirow{2}{*}{ p $^{*}$} \\
\cline { 2 - 5 } & $\mathrm{n}$ & $\%$ & $\mathrm{n}$ & $\%$ & \\
\hline Inattention & 14 & 3.50 & 36 & 8.00 & 0.006 \\
$\begin{array}{l}\text { Reported by parents } \\
\text { Reported by teachers }\end{array}$ & 35 & 8.80 & 46 & 10.20 & 0.481 \\
$\begin{array}{l}\text { Reported in both } \\
\text { contexts }\end{array}$ & 5 & 1.30 & 15 & 3.30 & 0.470
\end{tabular}

Hyperactivity

$\begin{array}{lccccc}\text { Reported by parents } & 45 & 11.40 & 130 & 15.30 & 0.003 \\ \begin{array}{l}\text { Reported by teachers } \\ \begin{array}{l}\text { Reported in both } \\ \text { contexts }\end{array}\end{array} & 12 & 8.80 & 49 & 10.90 & 0.32 \\ & 12 & 3.00 & 20 & 4.40 & 0.285 \\ \end{array}$

Household income

$\begin{array}{lcccc}\text { Less than BMMW } & 41 & 10.40 & 67 & 14.90 \\ \begin{array}{l}\text { One to less than two } \\ \text { times BMMW }\end{array} & 146 & 37.00 & 241 & 53.60 \\ \begin{array}{l}\text { Two to less than five } \\ \text { times BMMW }\end{array} & 137 & 34.70 & 115 & 25.60 \\ \begin{array}{l}\text { Five BMMW or more } \\ \text { Fin }\end{array} & 71 & 18.00 & 27 & 6.00\end{array}$

Mother's schooling $>0.001$

Incomplete primary

school

Complete primary

school

Incomplete high school $\quad 18 \quad 4.60 \quad 33 \quad 7.30$

Complete high school $\quad 132 \quad 33.40 \quad 156 \quad 34.60$

Higher education

$\begin{array}{llll}148 & 37.50 & 62 & 13.70\end{array}$

BMMW: Brazilian monthly minimum wage; ${ }^{*}$ chi-square test

report of inattention, agreement between parents/ caregivers and teachers regarding inattention, and parental report of hyperactivity were significantly associated with each other $(p<0.0001)$. It was also found that the DigitSpan test (forward order) was significantly associated with SNAP-IV ( $\mathrm{p}<0.001)$. Thus, only parental report of inattention was selected, since it was more strongly associated with the occurrence of caries.

The multivariate Poisson regression model revealed that three variables remained significant for explaining the occurrence of caries: mother's schooling, parental report of inattention, and span (maximum sequence) 
Table 4. Association between neuropsychological variables and occurrence of cavitated teeth.

\begin{tabular}{|c|c|c|c|c|c|}
\hline \multirow{2}{*}{ Variable } & \multicolumn{2}{|c|}{ Without cavitated teeth } & \multicolumn{2}{|c|}{ With cavitated teeth } & \multirow{2}{*}{$p^{*}$} \\
\hline & Mean (SD) & Median (q $1-q 3)$ & Mean (SD) & Median (q1-q3) & \\
\hline Digit Span test (forward order) & $4.95(1.07)$ & $5(4-5)$ & $4.79(1.00)$ & $5(4-5)$ & 0.066 \\
\hline Digit Span test (backward order) & $3.05(0.84)$ & $3(3-3)$ & $3.11(2.13)$ & $3(3-3)$ & 0.779 \\
\hline Corsi Block Tapping test (forward order) & $4.72(1.00)$ & $5(4-5)$ & $4.64(0.98)$ & $5(4-5)$ & 0.314 \\
\hline Corsi Block Tapping test (backward order) & $4.42(1.07)$ & $5(4-5)$ & $4.17(1.22)$ & $4(4-5)$ & 0.008 \\
\hline Raven (percentile) & $56.72(24.04)$ & $60(40-75)$ & $53.01(25.07)$ & $50(30-70)$ & 0.028 \\
\hline
\end{tabular}

*Mann-Whitney test.

Table 5. Univariate and multivariate Poisson regression considering occurrence of cavitated teeth as dependent variable and socio-demographic characteristics, SNAP questionnaire, and executive functions as independent variables.

\begin{tabular}{|c|c|c|c|c|c|c|c|c|}
\hline \multirow{3}{*}{ Poisson } & \multicolumn{4}{|c|}{ Univariate analysis } & \multicolumn{4}{|c|}{ Multivariate } \\
\hline & \multicolumn{3}{|c|}{$95 \% \mathrm{Cl}$} & \multirow{2}{*}{$p$} & \multicolumn{3}{|c|}{$95 \% \mathrm{Cl}$} & \multirow{2}{*}{$p$} \\
\hline & PR & Lower & Upper & & PR & Lower & Upper & \\
\hline \multicolumn{9}{|l|}{ Sex } \\
\hline Female & 1 & - & - & - & - & - & - & - \\
\hline Male & 1.044 & 0.920 & 1.185 & 0.507 & - & - & - & - \\
\hline Age (years) & 0.965 & 0.929 & 1.001 & 0.059 & - & - & - & - \\
\hline \multicolumn{9}{|l|}{ Household income } \\
\hline Five BMMW or more & 1 & - & - & - & - & - & - & - \\
\hline 2 to less than 5 times BMMW & 1.649 & 1.163 & 2.336 & 0.005 & - & - & - & - \\
\hline 1 to less than 2 times BMMW & 2.266 & 1.628 & 3.153 & $\leq 0.0001$ & - & - & - & - \\
\hline Less than BMMW & 2.264 & 1.587 & 3.229 & $\leq 0.0001$ & - & - & - & - \\
\hline Number of individuals living on income & 1.074 & 0.996 & 1.158 & 0.064 & - & - & - & - \\
\hline \multicolumn{9}{|l|}{ Mother's schooling } \\
\hline Higher education & 1 & - & - & - & 1 & - & - & - \\
\hline Complete high school & 1.830 & 1.447 & 2.315 & $\leq 0.0001$ & 1.798 & 1.422 & 2.273 & $\leq 0.0001$ \\
\hline Incomplete high school & 2.212 & 1.652 & 2.962 & $\leq 0.0001$ & 2.111 & 1.578 & 2.823 & $\leq 0.0001$ \\
\hline Complete primary school & 2.245 & 1.735 & 2.905 & $\leq 0.0001$ & 2.139 & 1.648 & 2.777 & $\leq 0.0001$ \\
\hline Incomplete primary school & 2.309 & 1.836 & 2.905 & $\leq 0.0001$ & 2.234 & 1.773 & 2.814 & $\leq 0.0001$ \\
\hline \multicolumn{9}{|l|}{ Father's schooling } \\
\hline Higher education & 1 & - & - & - & - & - & - & - \\
\hline Complete high school & 1.136 & 0.857 & 1.506 & 0.375 & - & - & - & - \\
\hline Incomplete high school & 1.423 & 0.997 & 2.032 & 0.052 & - & - & - & - \\
\hline Complete primary school & 1.604 & 1.213 & 2.123 & 0.001 & - & - & - & - \\
\hline Incomplete primary school & 1.608 & 1.250 & 2.069 & $\leq 0.0001$ & - & - & - & - \\
\hline Not inattentive - Parental report & 1 & - & - & - & 1 & - & - & - \\
\hline Inattentive - Parental report & 1.384 & 1.150 & 1.666 & 0.001 & 1.285 & 1.070 & 1.543 & 0.007 \\
\hline Not inattentive - Teachers' reports & 1 & - & - & - & - & - & - & - \\
\hline Inattentive - Teachers' reports & 1.075 & 0.879 & 1.315 & 0.481 & - & - & - & - \\
\hline Not inattentive - Parent/teacher agreement & 1 & - & - & - & - & - & - & - \\
\hline Inattentive - Parent/teacher agreement & 1.424 & 1.097 & 1.849 & 0.008 & - & - & - & - \\
\hline Not hyperactive - Parental report & 1 & - & - & - & - & - & - & - \\
\hline Hyperactive - Parental report & 1.282 & 1.110 & 1.482 & 0.001 & - & - & - & - \\
\hline Not hyperactive - Teachers' reports & 1 & - & - & - & - & - & - & - \\
\hline Hyperactive - Teachers' reports & 1.108 & 0.914 & 1.344 & 0.297 & - & - & - & - \\
\hline Not hyperactive - Parent/teacher agreement & 1 & - & - & - & - & - & - & - \\
\hline Hyperactive - Parent/teacher agreement & 1.183 & 0.897 & 1.559 & 0.233 & - & - & - & - \\
\hline Digit Span test (forward order) & 0.923 & 0.866 & 0.984 & 0.014 & - & - & - & - \\
\hline Digit Span test (Backward order) & 1.007 & 0.985 & 1.030 & 0.548 & - & - & - & - \\
\hline Corsi Block Tapping test (Forward order) & 0.945 & 0.886 & 1.008 & 0.084 & - & - & - & - \\
\hline Corsi (Backward order) & 0.907 & 0.862 & 0.955 & $\leq 0.0001$ & 0.940 & 0.896 & 0.987 & 0.013 \\
\hline Raven (Percentile) & 0.997 & 0.995 & 1.000 & 0.047 & 1.000 & 0.998 & 1.003 & 0.844 \\
\hline
\end{tabular}


Table 6. Multivariate Poisson regression considering occurrence of cavitated teeth as dependent variable and socio-demographic characteristics, parental reports of hyperactivity, and executive functions as independent variables.

\begin{tabular}{|c|c|c|c|c|}
\hline \multirow{2}{*}{ Poisson } & \multicolumn{3}{|c|}{ Multivariate $(95 \% \mathrm{Cl})$} & \multirow{2}{*}{$\mathrm{p}$} \\
\hline & PR & Lower & Upper & \\
\hline \multicolumn{5}{|l|}{ Mother's schooling } \\
\hline Higher education & 1 & -- & -- & -- \\
\hline Complete high school & 1.792 & 1.416 & 2.268 & $\leq 0.0001$ \\
\hline Incomplete high school & 2.120 & 1.584 & 2.835 & $\leq 0.0001$ \\
\hline Complete primary school & 2.152 & 1.660 & 2.790 & $\leq 0.0001$ \\
\hline Incomplete primary school & 2.212 & 1.754 & 2.790 & $\leq 0.0001$ \\
\hline Not hyperactive - Parental report & 1 & -- & -- & -- \\
\hline Hyperactive - Parental report & 1.152 & 1.002 & 1.325 & 0.047 \\
\hline Corsi Block Tapping test (backward order) & 0.941 & 0.897 & 0.987 & 0.013 \\
\hline Raven (Percentile) & 1.000 & 0.997 & 1.002 & 0.922 \\
\hline
\end{tabular}

on the Corsi Block Tapping test (backward order) (Table 5). The results of the multivariate analysis indicate that the prevalence rate of dental caries was twice as high in children whose mothers had lower levels of schooling. However, the prevalence ratio was reduced by $6 \%$ for every one-point increase on the Corsi Block Tapping test (backward order). Regarding inattention, children reported as inattentive by parents/caregivers had a $28 \%$ higher prevalence of cavitated teeth compared to children not reported as inattentive by parents/caregivers.

To test the influence of parental report of hyperactivity, this variable was incorporated into a multivariate model replacing the report of inattention (Table 6). Schooling remained significant, indicating that children whose mothers had a lower level of education were about twice as likely to have cavitated teeth $(\mathrm{p}<0.05)$. A better performance on the Corsi Block Tapping test (backward order) was a protective factor against the occurrence of cavitated teeth, as children with better performance had a $5.9 \%$ reduction in the prevalence of cavitated teeth. The performance on the Raven's Colored Progressive Matrices test was not a significant explanatory variable for the occurrence of caries. A parental report of hyperactivity was significantly associated with the occurrence of cavitated teeth, as children considered hyperactive by their parents/caregivers had a $15 \%$ higher prevalence rate of cavitated teeth.

\section{Discussion}

The present study evaluated the influence of signs of hyperactivity/inattention and executive functions on the occurrence of dental caries in children aged seven to 12 years in the city of Diamantina, Minas Gerais, Brazil. The prevalence of caries was $53.2 \%$, which is similar to the rate reported in the most recent national oral health survey ${ }^{23}$, which found a $56.5 \%$ prevalence rate of dental caries among 12-year-old children.

Regarding signs of ADHD, inattention was reported more by teachers $(9.50 \%)$ than parents/caregivers (5.90\%), whereas hyperactivity was reported more by parents/caregivers (15.30\%) than teachers (9.90\%). Considering the criterion of symptoms in both settings (family and school), the prevalence of inattention and hyperactivity was $2.40 \%$ and $3.80 \%$, respectively. These results contrast with the findings of another study also involving schoolchildren ${ }^{24}$, in which the prevalence of inattention and hyperactivity reported by teachers was higher than that reported by parents/caregivers.

When considering the fact that teachers reported a higher occurrence of attention deficit than did parents, it should be noted that the levels of parental education and household income were low. Previous studies report that parents with a low level of schooling tend to underestimate attention deficit in their children. ${ }^{24,25}$ Moreover, it is possible that a low socioeconomic status and lack of access to information on ADHD may have reduced the score in the parental reports of signs. ${ }^{24} \mathrm{It}$ is also possible that attention deficit is more evident to teachers because they are especially focused on academic performance. Thus, the classification of inattention may have been influenced by the child's performance at school. 
A study investigating the influence of cognitive impairment on the prevalence of dental caries in individuals with cerebral palsy showed that individuals with a poorer performance on Raven's Colored Progressive Matrices were more likely to have caries. ${ }^{26}$ In the present study, the performance on Raven's test was a significant predictor for the occurrence of caries when considered alone in the univariate regression analysis, but lost its statistical significance when considered in conjunction with other variables (mother's schooling, reports of inattention, reports of hyperactivity, and executive functions) in the multivariate model. This indicates that, when controlling for mother's schooling, executive functions have greater explanatory power with regard to caries than intellectual performance.

The socioeconomic status of the study population was low, as $58.60 \%$ of families declared earning an income of up to two times the Brazilian monthly minimum wage. Significant associations were found between the occurrence of dental caries and both mother's schooling and household income using the chi-square test. However, only mother's schooling was incorporated into the multivariate Poisson regression to avoid the possible occurrence of multicollinearity. In the univariate Poisson regression analysis, an association was found between household income and the occurrence of dental caries, with a lower prevalence rate of caries among higher income families. Despite trends of a significant reduction in epidemiological indicators, dental caries remains highly prevalent among children from families with a low socioeconomic status. ${ }^{27,28}$

The prevalence of dental caries was lower among children whose mothers had a higher level of schooling. Scientific evidence has indicated that low parental education, especially among mothers, is a predisposing factor for dental caries in children. 29,30,31 Moreover, a study on the determinants of dental caries reports that children whose mothers are less educated visit the dentist less frequently. ${ }^{32} \mathrm{~A}$ higher educational level often translates to better working conditions, a higher household income ${ }^{33}$, and better access to goods and services as well as the adoption of healthier habits. ${ }^{28}$ Moreover, studies indicate that individuals with a low level of schooling often have little knowledge with regard to health status and tend not to recognize the need for treatment. $34,35,36,37,38$

Children reported as inattentive by their parents/ caregivers had an increased prevalence of dental caries. This association was likely due to the negative influence that attention deficit exerts on activities of daily living carried out by the child in the home environment, with the possible adoption of inadequate oral hygiene habits. Similarly, children reported as hyperactive by parents/caregivers were more likely to have dental caries. One explanation for these findings is that children with ADHD have difficulty staying focused, which may result in a decrease in the effectiveness of brushing. ${ }^{13}$

A better performance on the Corsi Block Tapping test (backward order) was associated with a lower occurrence of dental caries. The backward order of this test is used to evaluate executive functions that involve planning, attention, working memory, and behavioral control based on motor coordination and visual-spatial memory. A previous study found that children with ADHD had poorer motor skills ${ }^{39}$, which could be one of the explanatory factors for a worse performance on the Corsi Block Tapping test (backward order). Thus, it is possible that children with ADHD have poor oral health due to problems with regard to motor coordination, which is fundamental to effective tooth brushing.

A recent study with a representative sample found no association between ADHD and oral health. ${ }^{40}$ The absence of an association may be due to the failure to investigate the different signs of ADHD. In the present study, the signs were analyzed separately and both inattention and hyperactivity were associated with the occurrence of caries. It should be noted that the prevalence ratio was higher for inattention, indicating that this sign is more strongly associated with the occurrence of caries in comparison to hyperactivity.

As caries is a multifactor disease, some important factors should also be taken into consideration, such as dietary habits and sugar intake. ${ }^{41}$ There is evidence that ADHD children consume carbohydrates and sweets more than children without this disorder. ${ }^{13}$ Some studies have also found a significant association between ADHD and obesity/overweight. ${ }^{42,43}$ As 
ADHD is a disorder characterized by inattention and impulsivity, changes in dietary habits may be related to these behavioral characteristics. Moreover, some parents faced with these characteristics may be more permissive, making dietary concessions that could facilitate the unregulated consumption of cariogenic foods. ${ }^{10}$

This study provides new evidence on what aspects related to ADHD are associated with dental caries. The fact that inattention and hyperactivity were associated with the outcome may assist in the planning of oral health programs for children with ADHD as well as the prioritization of resources for the implementation of prevention and health promotion policies for these children. However, the cross-sectional study design does not enable the establishment of causality and the associations should therefore be interpreted with caution. Longitudinal studies and case-control studies controlling for confounding factors such as dietary practices and oral hygiene habits are needed to allow a better understanding of factors associated with the higher occurrence of caries in individuals with signs of ADHD.

\section{References}

1. American Psychiatrlc Association. Diagnostic and statistical manual of Mental Disorders, 4th eiditon, text revision (DSM-IVTR). Washington, DC: American Psychiatry Association; 2000.

2. Rowland AS, Umbach DM, Catoe KE, Stallone L, Long S, Rabiner D et al. Studying the epidemiology of attentiondeficit hyperactivity disorder: screening method and pilot results. Can J Psychiatry. 2001 Dec;46(10):931-40. https://doi.org/10.1177/070674370104601005

3. Cuffe SP, Moore CG, McKeown RE. Prevalence and correlates of ADHD symptoms in the national health interview survey. J Atten Disord. 2005 Nov;9(2):392-401. https://doi.org/10.1177/1087054705280413

4. Blomqvist M, Ahadi S, Fernell E, Ek U, Dahllöf G. Dental caries in adolescents with attention deficit hyperactivity disorder: a populationbased follow-up study. Eur J Oral Sci. 2011 Oct;119(5):381-5. https://doi.org/10.1111/j.1600-0722.2011.00844.x

5. Blomqvist M, Holmberg K, Fernell E, Dahllöf $G$. A retrospective study of dental behavior management problems in children with attention and learning problems. Eur J Oral Sci. 2004 Oct;112(5):406-11. https://doi.org/10.1111/j.1600-0722.2004.00150.x

\section{Conclusion}

In conclusion, parental reports of attention deficit/ hyperactivity and executive functions evaluated using the Corsi Block Tapping test (backward order) were explanatory factors for the occurrence of dental caries after controlling for the influence of intelligence and mother's schooling. A better performance with regard to executive functions was associated with a lower prevalence rate of dental caries, whereas children considered inattentive and/or hyperactive by their parents/caregivers had a higher prevalence rate of dental caries.

\section{Acknowledgments}

This study was funded by the Brazilian funding agencies Coordenação de Aperfeiçoamento de Pessoal de Nível Superior (CAPES), Conselho Nacional de Desenvolvimento Científico e Tecnológico (CNPq) and Fundação de Amparo à Pesquisa do Estado de Minas Gerais (FAPEMIG). The funding providers had no role in the study design, data collection, data analysis, publishing decisions, or preparation of the manuscript.
6. Matza LS, Paramore C, Prasad M. A review of the economic burden of ADHD. Cost Eff Resour Alloc. 2005 Jun;3(3):5. https://doi.org/10.1186/1478-7547-3-5

7. Catalá-López F, Peiró S, Ridao M, Sanfélix-Gimeno G, Gènova-Maleras R, Catalá MA. Prevalence of attention deficit hyperactivity disorder among children and adolescents in Spain: a systematic review and metaanalysis of epidemiological studies. BMC Psychiatry. 2012 Oct;12(12):168. https://doi.org/10.1186/1471-244X-12-168

8. Barkley RA. Behavioral inhibition, sustained attention, and executive functions: constructing a unifying theory of ADHD. Psychol Bull. 1997 Jan;121(1):65-94. https://doi.org/10.1037/0033-2909.121.1.65

9. Centers for Disease Control and Prevention. 2017 [cited 2017 Jun 12]. Available from: https://www.cdc.gov/ncbddd/adhd/data.html

10. Broadbent JM, Ayers KM, Thomson WM. Is attention-deficit hyperactivity disorder a risk factor for dental caries? A case-control study. Caries Res. 2004 Jan-Feb;38(1):29-33. https://doi.org/10.1159/000073917 
11. Grooms MT, Keels MA, Roberts MW, Mclver FT. Caries experience associated with attention-deficit/ hyperactivity disorder. J Clin Pediatr Dent. 2005;30(1):3-7. https://doi.org/10.17796/jcpd.30.1.d3n7k5147r3ru571

12. Murray CM, Naysmith KE, Liu GC, Drummond BK. A review of attention-deficit/hyperactivity disorder from the dental perspective. N Z Dent J. 2012 Sep;108(3):95-101.

13. Chandra P, Anandakrishna L, Ray P. Caries experience and oral hygiene status of children suffering from attention deficit hyperactivity disorder. J Clin Pediatr Dent. 2009;34(1):25-9. https://doi.org/10.17796/icpd.34.1.n170271832662v44

14. Blomqvist M, Holmberg K, Fernell E, Ek U, Dahllöf G. Dental caries and oral health behavior in children with attention deficit hyperactivity disorder. Eur J Oral Sci. 2007 Jun;115(3):186-91. https://doi.org/10.1111/i.1600-0722.2007.00451.x

15. Hidas A, Noy AF, Birman N, Shapira J, Matot I, Steinberg $D$ et al. Oral health status, salivary flow rate and salivary quality in children, adolescents and young adults with ADHD. Arch Oral Biol. 2011 Oct;56(10):1137-41. https://doi.org/10.1016/i.archoralbio.2011.03.018

16. World Health Organization - WHO. Oral health surveys: basic methods. Geneva: World Health Organization; 1997.

17. Angelini AL, Alves ICB, Cust?dio EM, Duarte WF, Duarte JLM. Matrizes progressivas coloridas de Raven: escala especial: manual. São Paulo: CETEPP, 1999.

18. Ahn HJ, Chin J, Park A, Lee BH, Suh MK, Seo SW et al. Seoul Neuropsychological Screening Battery-dementia version (SNSB-D): a useful tool for assessing and monitoring cognitive impairments in dementia patients. J Korean Med Sci. 2010 Jul;25(7):1071-6. https://doi.org/10.3346/jkms.2010.25.7.1071

19. Goble DJ, Aaron MB, Warschausky S, Kaufman JN, Hurvitz $E A$. The influence of spatial working memory on ipsilateral remembered proprioceptive matching in adults with cerebral palsy. Exp Brain Res. 2012 Nov;223(2):259-69. https://doi.org/10.1007/s00221-012-3256-8

20. Bussing R, Fernandez M, Harwood M, Wei Hou, Garvan CW, Eyberg SM et al. Parent and teacher SNAP-IV ratings of attention deficit hyperactivity disorder symptoms: psychometric properties and normative ratings from a school district sample. Assessment. 2008 Sep;15(3):317-28. https://doi.org/10.1177/1073191107313888

21. Victora CG, Huttly SR, Fuchs SC, Olinto MT. The role of conceptual frameworks in epidemiological analysis: a hierarchical approach. Int J Epidemiol. 1997 Feb;26(1):224-7. https://doi.org/10.1093/ije/26.1.224

22. Victora CG, Huttly SR, Barros FC, Lombardi C, Vaughan JP. Maternal education in relation to early and late child health outcomes: findings from a Brazilian cohort study. Soc Sci Med. 1992 Ap;34(8):899-905. https://doi.org/10.1016/0277-9536(92)90258-R

23. Ministério da Saúde (BR). Secretaria de Atenção à Saúde. Departamento de Atenção Básica. Projeto SB Brasil 2010: condições de saúde bucal da população brasileira 2010: resultados principais. Brasília, DF: Ministério de Saúde; 2010.
24. Serra-Pinheiro MA, Mattos P, Angélica Regalla M. Inattention, hyperactivity, and oppositional- defiant symptoms in Brazilian adolescents: gender prevalence and agreement between teachers and parents in a non-English speaking population. J Atten Disord. 2008 Sep;12(2):135-40. https://doi.org/10.1177/1087054708314620

25. Weckerly J, Aarons GA, Leslie LK, Garland AF, Landsverk J, Hough RL. Attention on inattention: the differential effect of caregiver education on endorsement of ADHD symptoms. J Dev Behav Pediatr. 2005 Jun;26(3):201-8. https://doi.org/10.1097/00004703-200506000-00006

26. Moreira RN, Alcântara CE, Mota-Veloso I, Marinho SA, Ramos-Jorge ML, Oliveira-Ferreira F. Does intellectual disability affect the development of dental caries in patients with cerebral palsy? Res Dev Disabil. 2012 Sep-Oct;33(5):1503-7. https://doi.org/10.1016/j.ridd.2012.03.026

27. Vargas CM, Ronzio CR. Disparities in early childhood caries. BMC Oral Health. 2006 Jun;6(Suppl 1):53. https://doi.org/10.1186/1472-6831-6-S1-S3

28. Traebert J, Jinbo Y, Lacerda JT. Association between maternal schooling and caries prevalence: a cross-sectional study in southern Brazil. Oral Health Prev Dent. 2011;9(1):47-52. PMID:21594206

29. Saito SK, Deccico HMU, Santos MN. Efeito da pratica de alimentação infantil e de fatores associados sobre a ocorrência de carie dental em pré-escolares de 18 a 48 meses. Rev Odontol Univ São Paulo. 1999;13:5-11.

30. Peres KG, Bastos JR. Latorre MR. [Severity of dental caries in children and relationship with social and behavioral aspects]. Rev Saúde Pública. 2000 Aug;34(4):402-8. Portuguese. https://doi.org/10.1590/S0034-89102000000400014

31. Traebert J, Guimarães LA, Durante EZ, Serratine AC. Low maternal schooling and severity of dental caries in Brazilian preschool children. Oral Health Prev Dent. 2009;7(1):39-45.

32. Piovesan C, Antunes JL, Guedes RS, Ardenghi TM. Influence of self-perceived oral health and socioeconomic predictors on the utilization of dental care services by schoolchildren. Braz Oral Res. 2011 Mar-Apr;25(2):143-9. https://doi.org/10.1590/S1806-83242011005000004

33. Peres MA, Latorre MRO, Sheiham A, Peres KG, Barros FC, Hernandez PG et al. Social and biological early life influences on severity of dental caries in children aged 6 years. Community Dent Oral Epidemiol. 2005 Feb;33(1):53-63. https://doi.org/10.1111/j.1600-0528.2004.00197.x

34. Dewalt DA, Berkman ND, Sheridan S, Lohr KN, Pignone MP. Literacy and health outcomes: a systematic review of the literature. J Gen Intern Med. 2004 Dec;19(12):1228-39. https://doi.org/10.1111/j.1525-1497.2004.40153.x

35. Jackson R. Parental health literacy and children's dental health: implications for the future. Pediatr Dent. 2006 Jan-Feb;28(1):72-5.

36. Yin HS, Forbis SG, Dreyer BP. Health literacy and pediatric health. Curr Probl Pediatr Adolesc Health Care. 2007 Aug;37(7):258-86. https://doi.org/10.1016/i.cppeds.2007.04.002 
Dental caries in schoolchildren: influence of inattention, hyperactivity and executive functions

37. Lee JY, Rozier RG, Lee SY, Bender D, Ruiz RE.

Development of a word recognition instrument to test health literacy in dentistry: the REALD-30: a brief communication. J Public Health Dent. 2007;67(2):94-8. https://doi.org/10.1111/j.1752-7325.2007.00021.x

38. Ramos-Jorge ML, Ramos-Jorge J, Mota-Veloso I, Oliva KJ, Zarzar PM, Marques LS. Parents' recognition of dental trauma in their children. Dent Traumatol. 2013 Aug;29(4):266-71. https://doi.org/10.1111/edt.12005

39. Karatekin C, Markiewicz SW, Siegel MA. A preliminary study of motor problems in children with attention-deficit/ hyperactivity disorder. Percept Mot Skills. 2003 Dec;97(3 Pt 2):1267-80. https://doi.org/10.2466/pms.2003.97.3f.1267

40. Kohlboeck G, Heitmueller D, Neumann C, Tiesler C, Heinrich J, Heinrich-Weltzien R et al. Is there a relationship between hyperactivity/inattention symptoms and poor oral health? Results from the GINIplus and LISAplus study. Clin Oral Investig. 2013 Jun;17(5):1329-38. https://doi.org/10.1007/s00784-012-0829-7

41. Tinanoff N, Palmer CA. Dietary determinants of dental caries and dietary recommendations for preschool children. J Public Health Dent. 2000;60(3):197-206. https://doi.org/10.1111/j.1752-7325.2000.tb03328.x

42. Cortese S, Vincenzi B. Obesity and ADHD: clinical and neurobiological implications. Curr Top Behav Neurosci. 2012;9:199-218. https://doi.org/10.1007/7854_2011_154

43. Cortese S, Moreira-Maia CR, St Fleur D, Morcillo-Peñalver C, Rohde LA, Faraone SV. Association Between ADHD and Obesity: A Systematic Review and Meta-Analysis. Am J Psychiatry. 2016 Jan;173(1):34-43. https://doi.org/10.1176/appi.ajp.2015.15020266 